\title{
Classification: The Analyses of the Psychometric Performances' Effects on the Special Needs Offenders Program
}

\author{
Park E. Atatah1, Catherine W. Kisavi-Atatah², Angela Branch-Vital² \\ ${ }^{1}$ College of Security and Criminal Justice "Social Behavioral Sciences", University of Phoenix, Phoenix, AZ, USA \\ ${ }^{2}$ Prairie View A\&M University, Prairie View, TX, USA \\ Email: peatatah@yahoo.com,ckisavi@yahoo.com, albranch-vital@pvamu.edu
}

Received 12 April 2016; accepted 23 May 2016; published 26 May 2016

Copyright (C) 2016 by authors and Scientific Research Publishing Inc.

This work is licensed under the Creative Commons Attribution International License (CC BY).

http://creativecommons.org/licenses/by/4.0/

(c) (i) Open Access

\section{Abstract}

The present study aims to examine the roles classification of special needs offenders (SNOs) played in their group's marginal propensity to successfully or unsuccessfully complete parole supervision due to the individual and collective performances in-between and in-within the classified group known as special needs offenders program (SNOP) caseload. In this study, compliance or noncompliance of SNOs policies or special conditions' violations was seen as the determinate supervision that affects SNOs psychometric performances. SNOs were made up of mental impairment (MI), mental retardation (MR), terminally ill (TI), physical handicapped (PH), or medically recommended intensive supervision (MRIS) offenders. The Administrative Parole Hearings in three major counties in Region 3 Texas between 2008 and 2009 were analyzed. The study found that in all areas dealing with violations and hearing process, MI responded excessively in-between and in-within $92 \%$ to $100 \%$ in all measurement categories. Additionally, the study found that of the 1877 special needs offenders program (SNOP) hearings conducted in Region 3 between 2008 and 2009, MI accounted for $90 \%$ or 699 out of 774 of offenders not revoked. Within the same period, MI offenders accounted for approximately $93 \%$ or 269 out of 291 of paroles that were revoked. Also, MI offenders accounted for $93 \%$ or 641 out of 689 transfers to ISF facilities, $100 \%$ transfer to SAFPF, and for a $\mathbf{1 0 0 \%}$ of all reopened revocation SNOs hearings in Region 3. Practically, MI showed overwhelming psychometric performances effects on the SNOP caseload. The implication of this study was to assist criminal justice officials, public health officials, public policy decision makers, and even for profit organizations to rethink, refocus, and revisit their SNOs management modalities, policies, and their methodologies, which could eventually bring some positive social changes to the SNOs statewide and possibly beyond.

\section{Keywords}

Psychometric, Performances Effects, Offenders, Special Needs Offenders, Responsivity, Criminal 


\section{Justice Over, Under, or No Performances}

\section{Introduction}

The purpose of this study was to examine the roles classification of special needs offenders (SNOs) during parole supervision in the state of Texas played in the SNOs' compliance or noncompliance. In this study, compliance or noncompliance of SNOs policies or special conditions' violations was seen as the supervision determinate that affects SNOs psychometric performances. Special needs offenders (SNOs) are offenders diagnosed with some form of psychiatric, psychological, or physical condition that limits their day-to-day living abilities. The Texas Department of Criminal Justice-Parole Division (TDCJ-PD) (2011) [1] classified SNOs as offenders who are diagnosed with some forms of mental or physical conditions and they are assigned to be supervised in the special needs offenders program (SNOP) caseload under the super or specialized intensive-1 (SI-1) supervision level. The SI-1 supervision level requires a minimum of three face-to-face monthly contacts with the SNOs and a minimum of two or more monthly collateral contacts with treatment providers; significant others such as wives, husbands, relatives, and families of offenders; the sponsors of the SNOs; and treatment providers to mention a few.

However, SI-1 supervision level is higher than those levels applied in the supervision of violent offenders such as sex offenders without sexual conviction, drug dealers, arsonists, armed robbers, substances and alcohol abusers, domestic violence offenders, driving while intoxicated (DWI) offenders, and murderers who may be supervised in sex offenders caseload or electronic monitoring caseload [1]-[3]. These are populations supervised by TDCJ-PD (2011) [1] on regular caseloads that required fewer monthly contacts than those imposed and classified on the SNOs caseload. These supervision levels include maximum level, requiring two contacts monthly office and home visits; medium level, requiring one office visit monthly, and one home visit every other month; minimum level requiring one office visit monthly, one home visit every 6 month quarterly reports, requiring one office visit every 3 months and one home visit every year; and annual reports requiring one office visit yearly. These supervision levels are lower than the SI-1 supervision level. Beside the drawbacks associated with the day to day lives' activities of the SNOs, comparing them to report more often than regular offenders is disturbing. However, TDCJ-PD since 1995 argued that the fundamental principle behind SNOP caseload under the supervision of SI-1 is to successfully supervise SNOs, giving them unequivocal opportunities effectively, efficiently, and proficiently complete their parole supervisions. The reality of the above argument still remains unknown in 2016. As such, the focus of this study was to look into the roles classification of SNOs played in their groups' marginal propensity to successfully or unsuccessfully complete parole supervision due to the individual and collective psychometric performances' effects in-between and in-within the classified group known as SNOs in the SNOP caseload.

\section{Literature Review}

Many studies have been conducted on the ability or inability of the SNOs' compliance while on community supervision or probation, parole, or incarcerated. For example, Bernstein [4]-[8] found that SNOs should not be treated differently than other offenders during parole supervision, community supervision (probation), or while incarcerated. Yet, the TDCJ-PD supervises its SNOs at one of the highest levels of supervision due to unproven assumptions and preconceptions that these offenders may be more likely to reoffend than regular offenders. SNOs in Austin, Colorado, and Fort Bend Counties, Texas, are placed on SI-1 level of supervision. SI-1 level of supervision is standardized when dealing with SNOs in the state of Texas among other specialized caseloads. This supervision level requires a minimum of five or more monthly contacts, as compared to one to two monthly contacts for most regular offenders' caseloads. These regular offenders' caseloads may include murderers, drug dealers, arsonists, and sex offenders without sexual convictions.

SI-1 supervision level imposition is based on the perceptions and assumptions of TDCJ-PD leadership that SNOs are more likely to reoffend as compared to regular offenders. However, information obtained from federal Department of Justice (DOC) proved contrarily to the above perceptions. According to TDCJ-PD [1]) policy, this contact level is not subject to change, regardless of compliance levels, risks factors, or need factors associated with the individual offender. This is contrary to the supervision levels of regular offenders as well as other 
specialized caseloads that periodically change, due to associated recidivism factors. The policies concerning SNOs supervision that were implemented by TDCJ-PD leadership could be subjective, based on perceptions and assumptions. Additionally, repeated efforts to have TDCJ-PD leadership reduce SNOs supervision level, based on compliance and other associative recidivism factors, have failed.

Such supervisory implications (factors that impact SNOs' compliance) include an inability to report as required by SI-1 supervision level, disagreements with SNOs' sponsors, lack of transportation, and inability to meet other special needs treatments requirements. TDCJ-PD [1] defined SNOs as an offender that has some form of mental impairment (MI), mental retardation (MR) with adaptive hardships prior to the age of 18, terminally ill (TI), physical handicapped (PH), or medically recommended intensive supervision (MRIS). These offenders are supervised in the SNOs' caseload. In light of this definition and approach, SNOs may need specialized personnel to work with this population of offenders in order for them to complete parole supervision successfully. However, the supervision implications created by the SI-1 supervision level make it challenging to find sustainable specialized parole officers for this caseload. As a result, the average special needs specialized officer (SNSO) lasts less than 3 years on the caseload due to associated social and supervision implications related to SNOs' inability to comply with parole supervision rules and conditions.

As stipulated, all offenders should and must be assessed with some form of RNR instruments when debating about which supervision levels are appropriate and applicable for certain offenders [9]-[12]. Although, the TDCJ-PD (2011) also uses this approach in the assessments and reassessments of regular and specialized offenders, including sex offenders (SO) who use Static 99, SNOs are not covered during these assessments and reassessments processes. Instead, SNOs are placed in a blanket supervision level (one supervision level for all SNOs regardless of RNR factors) which remains unchanged until completion of parole supervision or death. It is simply a mentality of ideology that "One size fits all”. Researchers [13]-[16] have indicated that individualized programs are useful during supervision of offenders; less is known about the roles supervision levels (personnel/professional involvements with offenders) play in offenders' ability to successful or unsuccessful complete parole supervision. While these literatures addressed the importance of what is considered as reasonable versus unreasonable accommodations when dealing with SNOs, they did not address the supervision implications of the classification's roles on the SNOs compliances. This deficiency in literature was the focus of this study.

\section{Theoretical Framework}

This study used two theoretical frameworks as lens of analyses. These theories were Risk/Needs/Responsivity (RNR) theory and social construction and reconstruction ideology of reality theory.

\subsection{Risks/Needs/Responsivity (RNR) Theory}

While the research of Lurigio et al. [8] may be used as a determinant of excessive or less involvement during the supervision of SNOs known as accommodation, it was not applicable to its relationship with recidivism rates of SNOs. Therefore, the theory of RNR by Bonta and Andrews [9] [11] [17] was examined to isolate supervision levels of offenders in relationship to the risks/needs factors associated with recidivism rates. According to Andrews and Bonta [17], the three core principles can be stated as follows:

Risk principle: Match the level of service to the offender's risk to re-offend.

Need principle: Assess criminogenic needs and target them in treatment.

Responsivity principle: Maximize the offender's ability to learn from a rehabilitative intervention by providing cognitive behavioral treatment and tailoring the intervention to the learning style, motivation, abilities and strengths of the offender. (p. 1)

Furthermore, Andrews et al. [9], and Ward et al. [11] examined the seven major risks/needs factors associated with recidivism rates of most offenders, along with some minor risks/needs factors. A comprehensive analysis of the roles the SI-1 supervision level plays in SNOs' recidivism rates was conducted comparing these RNR factors. Also, a comparison of the study's findings of SNOs recidivism rates was compared against those of SNOs in the same classification to determine whether if SNOs could be supervised at lower levels of supervision with possible reduced recidivism rates in the long or short run. Also, the primary goal of the risks/needs/responsivity theory is to classify all offenders based on the above pinpointed factors to determine offenders' level of supervision. Beside the above, the secondary goal of using RNR's classification model is to effectively, efficiently, and 
proficiently supervise offenders based on their levels of supervision. Essentially, RNR stressed that responsivity is the key measurements point of the definition of proper, low, average, or overdose due to the ways offenders' response to assigned supervision levels. In this study, RNR theory was used as a lens of data analyses. The internal and external consistencies of SNOs' compliances and possible noncompliance with supervision policies known as psychometric performances' effects on SNOs in this study were measured using RNR theory as a lens of analysis.

\subsection{Social Construction Ideology of Reality Theory}

While RNR theory by Andrews and Bonta [17] was used by the TDCJ-PD in case classification and assignment of supervision levels to regular offenders (ROs), the TDCJ-PD organizational policies/directives did not state the origin of the SI-1 supervision level. SNOs are not entitled to such supervision levels' classification due to SI-1 supervision level. Also, these policies/directives did not state that the origin of the SI-1 supervision level was the one and only appropriate and applicable supervision level for SNOs. Although Lurigio et al. [8] questioned of the meaning of involvements/accommodations, Lurigio et al. referred to it as supervision levels with SNOs in treatment, incarcerated, under parole supervision or under community supervision, Lurigio et al. did not address the origin of SI-1 supervision level. The SI-1 level of supervision imposed on SNOs in Austin, Colorado, and Fort Bend Counties, Texas, originated from organizational application of the social construction of reality theory that was developed by the leadership culture of TDCJ-PD that SNOs are more likely to reoffend than regular offenders. However, TDCJ-PD statistics regarding recidivism rates contradicts the development formulas behind the SI-1 level of supervision when dealing with SNOs.

However, closely looking into the origin of SI-1 in relationship to the social construction of reality theory shed some lights. For example, Berger and Luckmann [18] developed their idea of social reality in the Durkheimian theory and French school of sociology. Berger and Luckmann [18] believed that:

Our view of the nature of social reality is greatly indebted to Durkheim and his school in French sociology, though we have modified the Durkheimian theory of society by the introduction of a dialectical perspective derived from Marx and an emphasis on the constitution of social reality through subjective meanings derived from Weber. (p. 15)

Berger and Luckmann believed that most societal ideologies are originated from the understanding and interpretations of ideas which involves subjective approaches rather than objective reasoning. Also, that if these subjective approaches are monitor and verified repeatedly, they eventually become the norms through which societal ideas are shaped, developed, and implemented.

Berger and Luckmann [18] emphasized, "The language used in everyday life continuously provides me with the necessary objectifications and posits the order within which these make sense and within which everyday life has meaning for me” (p. 21). Berger and Luckmann believed that language makes subjectivity "more real” (p. 36), not only for conversational partners, but also for oneself. Therefore, the capacity of language to identify and preserve an individual's subjectivity, albeit with modification, is conserved even after face-to-face interaction is over. Wilden (1987 [19]) asserted:

Ideologies are by nature symbolic: what they symbolize may be both imaginary and real, reality being the ultimate test of their validity. They are transmitted between people by every available means: ritual, schooling, clothing, religion, jokes, games, myths, gestures, ornaments, entertainment (p. 91).

Language becomes a person's primary reference to everyday life. In content and context, Berger and Luckmann (1966 [18]) and Wilden [19] implied that any form of ideologies that led to policies' applications is systematically driven from individual gossips to groups that spread like wildfires. However, the spreads maybe so contagious that public and private organizations' decision makers use these rumors and myths as yardsticks in their policies decision making processes. But, the question now becomes is the classification of SNOs and the implementation of SI-1 level of supervision internally and externally effective, efficient, and proficient? This still remained unknown. In fact, it should be noted that the theoretical contents and contexts of the classification of SNOs is simply the efficacy of SNOs supervision. Contrarily, the internal and external compliances and noncompliance performances in-between and in-within the classified SNOs in SNOP caseload remains a mystery since implementation in 1995 [9] [11] [17]. Based on the above theoretical analyses, possibly SI-1 supervision 
level maybe motivated by social construction or possibly reconstruction of ideologies of reality theory; but, the realities behind the implementation of this policy originality remained unknown. In other words, the classification of SNOs under the supervision of the higher levels (SI-1) than needed supervision levels fell under the primary definition of social construction or even reconstruction of ideologies of reality theory, which was also used as a lens of data analyses in this classification effects' study.

\section{Research Questions}

This quantitative research study investigated two major research questions. These questions were:

1) Research Question 1. RQ 1:

What are the relationships between classification of SNOs and the implementation of SI-1 in the psychometric effects of offenders' performances?

2) Research Question 2. RQ 2:

What are the relationships between classification of SNOs and the implementation of SI-1 in the psychometric effects of offenders' performances collectively and individualized supervision?

\section{Hypotheses}

We hypothesized this study with two major hypotheses which were:

1) Alternative Hypothesis H11:

There was a direct relationship between classification of SNOs and the implementation of SI-1 in the psychometric effects of offenders' performances.

\section{2) Null Hypothesis H01:}

There was no relationship between classification of SNOs and the implementation of SI-1 in the psychometric effects of offenders' performances.

\section{Methodology}

These measurements concentrated on general descriptive statistics, percentile values, central tendencies, dispersions, and distribution of data, along with one-way sample statistics test, and a confidence interval differences test was set at $<0.05$ or $<0.95$. Nominal scale was used as the scale of measurement in this study. Non-Experimental Descriptive study relies on the statistical analyses of existing secondary or primary data, through comprehensive measurements of the above mentioned measurements' perimeters. The most significant reason of choosing such design for this study is the lack of participants' exposure to treatment. Offenders are vulnerable populations and exposing them to treatment undermines their marginal propensities to successfully complete parole supervision; among other drawbacks, to mention a few [20]-[24]. The above mentioned measurements shed some variances' lights in-between and in-within the groups' overall performances differences.

Beside the above, in this study Analysis of variance-simultaneous component analysis (ASCA or ANOVASCA) was used to find the partitions variations which enabled the interpretations of the effects or factors of performances in-within and in-between the SNOs population within the SNOP caseload [25]-[28]. As summed by the above researchers, even though the effect estimates are multivariate, interpretation of these effects estimates is not intuitive, it points out the roles individual group play in between and in within any classification of data. Essentially, by applying ASCA or ANOVA-SCA on the effect estimates one gets a simple interpretable result. Additionally, in case of more than one effect this method estimates the effects in such a way that the different effects are not correlated. Based on the above, ASCA or ANOVA-SCA shed some lights on the roles SI-1 played within the SNOs' performances collectively and individually with the SNOP caseload population. Statistical Package for Social Sciences (SPSS) 21 version was used to analyze the data for this study.

\section{Assumptions}

We conducted this study with three major assumptions in mind. These assumptions were;

Assumption 1:

Classification of SNOs and the implementation of SI-1 lead to psychometric effects of offenders' groups' overly performances.

Assumption 2: 
Classification of SNOs and the implementation of SI-1 lead to psychometric effects of offenders' group under performances.

\section{Assumption 3:}

Classification of SNOs and the implementation of SI-1 lead to psychometric effects of offenders' group no or zero performances.

As previously stated above, in this study the group over, under, and no performances is known as the psychometric performances effects of the SNOs in the SNOP caseload.

\section{Data Collection}

\subsection{Classification of Data}

As previously stated, TDCJ-PD (2011) defined SNOs as an offender that has some form of mental impairment (MI), mental retardation (MR) with adaptive hardships prior to the age of 18 , terminally ill (TI), physical handicapped (PH), or medically recommended intensive supervision (MRIS). Based on the above classification of SNOs in SNOP caseload, this study classified the data into the below enlisted areas.

1) mental impairment (MI)

2) mental retardation (MR)

3) terminally ill (TI)

4) physical handicapped (PH) and

5) Medically recommended intensive supervision (MRIS).

It should be noted that terminally ill (TI) and physically handicapped (PH) were collectively classified in a team within the SNOs group as TI/PH.

\subsection{Population of SNOs in SNOP Caseload}

MI accounts for about $60 \%$ of the SNOP caseload population of SNOs; and collectively, MR, TI/PH, and MRIS account for about $40 \%$ of the total population. Due to the fact that offenders in general are considered as vulnerable population, it should be noted that SNOs are more ultra vulnerable offenders due to the implications and complexities associated with their supervision and management. As a result, the data selected excluded all offenders' demographics such as date of birth (DOB), Texas Department of Criminal Justice-Parole Division identification numbers (TDCJ-PD \#), State Identification \# (SID), age, gender, and years of supervision, release dates and discharge dates. These identifiers personal demographics were all excluded as to protect the interests and privacies of the participants in the study. Also, the violations of rules of release and special conditions were classified into compliances and noncompliance. Additionally, all noncompliance which was measured in this study was classified as over performances, under performances, and no or zero performances.

\subsection{Compliances and Noncompliance Recorded as Psychometric Performances' Effects by Definitions}

1) Over performances: By definition associated with this study, over performances are considered as SNOs who accounted for more revocation hearings activities in the below 6 enlisted hearings categories which are considered as compliances or noncompliance.

2) Under performances: By definition associated with this study are considered as SNOs who accounted for average or below revocation hearings categories which are considered as compliances or noncompliance.

3) No or zero performances: By definition associated with this study are considered as SNOs who accounted for "none or zero" revocation hearings categories which are considered as compliances or noncompliance.

This classified definition in this study was recorded as such due to the possibly psychometric performances outcomes known as effects.

\section{Data Collection Process}

As previously stated above about the vulnerability of the SNOs in the SNOP caseload, a request to release Administrative Hearings Records conducted on these clients between 2008 and 2009 were submitted to the Texas Board of Pardon and Parole (BPP). Among the data that were approved and released to these researchers was a 
directive to public records of BPP FY 2008 and FY 2009 in Region 3 SNOP caseload Administrative Hearings Records, which comprised of $\mathbf{1 8 7 7}$ SNOs and analyzed in this study [29]-[31]). Due to the total of $\mathbf{1 8 7 7}$ hearings conducted in Region 3 between 2008 and 2009, since the total offenders in SNOP caseload was not disclosed before the hearings, the statistical formula was used to estimate the individual classification to be $\mathbf{6 0 \%}$ MI to $\mathbf{4 0 \%}$ to the others or 1126 for MI and 751 for MR, TI/PH, and MRIS. Among other released data, the above highlighted was used in this research study singularly due to the data type and possibly statistical robustness.

\section{Results of the Study}

Beside the above identified areas, this study analyzed data performances in the following areas. These areas are classified into six categories based on the factors associated with the Texas hearing processes with offenders in general. These categories are;

1) Not Revoked

2) Revoked

3) Transfer to ISF Facility

4) SAFPF

5) Reopened Revocation Hearing

6) Go to Revocation Hearing

The key for ISF means Intermediate Sanction Facility and SAFPF means Substance Abuse Felony Punishment Facility. These six categories were statistically coded as the psychometric performances of SNOs in SNOP caseload in Region 3 parole Administrative Hearings between 2008 and 2009. For further clarification, Region 3 has 7 major parole officers in Houston Harris County, Texas and 4 parole offices in the close surrounding counties.

Table 1 showed no missing data and all data were valid. The range varied from 686 to 9 cases in some areas. The maximum was 699 while the minimum was 0 in some cases. The variations were significantly different in most areas as showed (see Table 1).

Table 1. Descriptive statistics for SNOs.

\begin{tabular}{|c|c|c|c|c|c|c|}
\hline \multicolumn{7}{|c|}{ Statistics } \\
\hline & Not Revoked & Revoked & $\begin{array}{l}\text { Transfer to ISF } \\
\text { Facility }\end{array}$ & SAFPF & $\begin{array}{c}\text { Reopen Revocation } \\
\text { Hearing }\end{array}$ & $\begin{array}{c}\text { Go to Revocation } \\
\text { Hearing }\end{array}$ \\
\hline Valid & 4 & 4 & 4 & 4 & 4 & 4 \\
\hline Missing & 0 & 0 & 0 & 0 & 0 & 0 \\
\hline Mean & 193.50 & 72.75 & 172.25 & 2.25 & 1.50 & 27.00 \\
\hline Std. Error of Mean & 168.601 & 65.43 & 156.31 & 2.250 & 1.50 & 24.003 \\
\hline Median & $31.00^{\mathrm{a}}$ & $8.50^{\mathrm{a}}$ & $21.50^{\mathrm{a}}$ & $2.25^{\mathrm{a}}$ & $1.50^{\mathrm{a}}$ & $3.50^{\mathrm{a}}$ \\
\hline Mode & $13.00^{\mathrm{b}}$ & $5.00^{\mathrm{b}}$ & $5.00^{\mathrm{b}}$ & 0.00 & 0.00 & $2.00^{\mathrm{b}}$ \\
\hline Std. Deviation & 337.21 & 130.86 & 312.62 & 4.50 & 3.00 & 48.01 \\
\hline Variance & 113707.67 & 17124.25 & 97730.25 & 20.25 & 9.000 & 2304.67 \\
\hline Skewness & 1.99 & 1.998 & 1.995 & 2.000 & 2.000 & 1.998 \\
\hline Std. Error of Skewness & 1.014 & 1.014 & 1.014 & 1.014 & 1.014 & 1.014 \\
\hline Kurtosis & 3.98 & 3.992 & 3.985 & 4.000 & 4.000 & 3.994 \\
\hline Std. Error of Kurtosis & 2.62 & 2.62 & 2.619 & 2.619 & 2.619 & 2.619 \\
\hline Range & 686.00 & 264.00 & 636.00 & 9.00 & 6.00 & 97.00 \\
\hline Minimum & 13.00 & 5.00 & 5.00 & 0.00 & 0.00 & 2.00 \\
\hline Maximum & 699.00 & 269.00 & 641.00 & 9.00 & 6.00 & 99.00 \\
\hline Sum & 774.00 & 291.00 & 689.00 & 9.00 & 6.00 & 108.00 \\
\hline
\end{tabular}

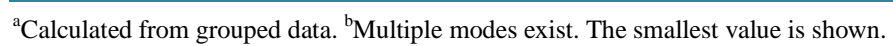


Table 2 showed the cumulative frequencies of the Not Revoked SNOs between 2008 and 2009; and MI accounted for 699 SNOS while the remaining three grouped SNOs collectively accounted for 75 cases (see Table 2).

Table 3 showed the cumulative frequencies of the Revoked SNOs between 2008 and 2009; and MI accounted for 269 SNOS while the remaining three grouped SNOs collectively accounted for 22 cases (see Table 3).

Table 4 showed the cumulative frequencies of the SNOs Transferred to ISF Facility between 2008 and 2009; and MI accounted for 641 SNOs; while the remaining three grouped SNOs collectively accounted for 48 cases (see Table 4).

Table 5 showed the cumulative frequencies of the SNOs Transferred to SAFPF Facility between 2008 and 2009; and MI accounted for 9 SNOs; while the remaining three grouped SNOs collectively accounted for 0 cases (see Table 5).

Table 6 showed the cumulative frequencies of the SNOs for Reopened revocation hearings between 2008 and 2009; and MI accounted for 6 SNOs; while the remaining three grouped SNOs collectively accounted for 0 cases (see Table 6).

Table 7 showed the cumulative frequencies of the SNOs with decision to go to revocation hearings between 2008 and 2009; and MI accounted for 99 SNOs; while the remaining three grouped SNOs collectively accounted for 9 cases (see Table 7).

Table 2. Not revoked SNOs.

\begin{tabular}{|c|c|c|c|c|c|}
\hline \multicolumn{6}{|c|}{ Not Revoked SNOs Cumulative Frequency } \\
\hline & & Frequency & Percent & Valid Percent & Cumulative Percent \\
\hline \multirow{5}{*}{ Valid } & 13.00 & 1 & 25.0 & 25.0 & 25.0 \\
\hline & 21.00 & 1 & 25.0 & 25.0 & 50.0 \\
\hline & 41.00 & 1 & 25.0 & 25.0 & 75.0 \\
\hline & 699.00 & 1 & 25.0 & 25.0 & 100.0 \\
\hline & Total & 4 & 100.0 & 100.0 & \\
\hline
\end{tabular}

Table 3. Revoked SNOs.

\begin{tabular}{|c|c|c|c|c|c|}
\hline \multicolumn{6}{|c|}{ Revoked SNOs Cumulative Frequency } \\
\hline & & Frequency & Percent & Valid Percent & Cumulative Percent \\
\hline \multirow{5}{*}{ Valid } & 5.00 & 1 & 25.0 & 25.0 & 25.0 \\
\hline & 6.00 & 1 & 25.0 & 25.0 & 50.0 \\
\hline & 11.00 & 1 & 25.0 & 25.0 & 75.0 \\
\hline & 269.00 & 1 & 25.0 & 25.0 & 100.0 \\
\hline & Total & 4 & 100.0 & 100.0 & \\
\hline
\end{tabular}

Table 4. Transfered to ISF Facility.

\begin{tabular}{|c|c|c|c|c|c|}
\hline \multicolumn{6}{|c|}{ Transferred to ISF Facility Frequency } \\
\hline & & Frequency & Percent & Valid Percent & Cumulative Percent \\
\hline \multirow{5}{*}{ Valid } & 5.00 & 1 & 25.0 & 25.0 & 25.0 \\
\hline & 17.00 & 1 & 25.0 & 25.0 & 50.0 \\
\hline & 26.00 & 1 & 25.0 & 25.0 & 75.0 \\
\hline & 641.00 & 1 & 25.0 & 25.0 & 100.0 \\
\hline & Total & 4 & 100.0 & 100.0 & \\
\hline
\end{tabular}


Table 5. SAFPF.

\begin{tabular}{cccccc}
\hline \multicolumn{5}{c}{ SAFPF Frequency } \\
\\
& & Frequency & Percent & Valid Percent & Cumulative Percent \\
\hline \multirow{3}{*}{ Valid } & 0.00 & 3 & 75.0 & 75.0 & 75.0 \\
& 9.00 & 1 & 25.0 & 25.0 & 100.0 \\
& Total & 4 & 100.0 & 100.0 & \\
\hline
\end{tabular}

Table 6. Reopended revocation hearings for SNOs.

\begin{tabular}{cccccc}
\hline \multicolumn{5}{c}{ Reopened Revocation Hearings for SNOs } \\
\hline \multirow{3}{*}{ Valid } & Frequency & Percent & Valid Percent & Cumulative Percent \\
\hline & 0.00 & 3 & 75.0 & 75.0 & 75.0 \\
& 6.00 & 1 & 25.0 & 25.0 & 100.0 \\
& Total & 4 & 100.0 & 100.0 & \\
\hline
\end{tabular}

Table 7. Go to revocation hearings for SNOs.

\begin{tabular}{lccccc}
\hline \multicolumn{5}{c}{ Go to Revocation Hearings for SNOs } \\
\hline & Frequency & Percent & Valid Percent & Cumulative Percent \\
\hline \multirow{4}{*}{ Valid } & & 1 & 25.0 & 25.0 & 25.0 \\
& 3.00 & 1 & 25.0 & 25.0 & 50.0 \\
& 4.00 & 1 & 25.0 & 25.0 & 75.0 \\
& 99.00 & 1 & 25.0 & 25.0 & 100.0 \\
& Total & 4 & 100.0 & 100.0 & \\
\hline
\end{tabular}

Table 8 showed that of 774 SNOs, who were not revoked, 699 were MI and the rest were MR, TI/PH and MRIS. Furthermore, 641 out 689 sent to ISF were MI and 269 out 291 who were revoked were MI as well (see Table 8).

Table 9 showed that of 1877 SNOs analyzed in this MI accounted for 90\% Not Revoked, 92\% Revoked, and 93\% were sent to ISF, and $100 \%$ to SAFPF and $100 \%$ cases were reopened (see Table 9).

Figure 1 showed a mean of 193 and Std. Dev of 337 SNOs who were not revoked (see Figure 1).

Figure 2 showed a mean of 73 and Std. Dev of 131 SNOs who were revoked (see Figure 2).

Figure 3 showed a mean of 172 and Std. Dev of 312 SNOs who were sent to ISF facility (see Figure 3).

Figure 4 showed a mean of 2.25 and Std. Dev of 4.50 SNOs who were sent to SAFPF (see Figure 4).

Figure 5 showed a mean of 1.50 and Std. Dev of 3.00 required a reopen of revocation hearings (see Figure 5).

Figure 6 showed a mean of 27 and Std. Dev of 48 SNOs to go to revocation hearings (see Figure 6).

Figure 7 showed the pie chart visual representation (color coded) of SNOs offenders who were transferred to ISF after their administrative parole hearings. The low was 5; while the high was 641 MI offenders (see Figure 7).

Figure 8 showed the pie chart visual representation (color coded) of SNOs offenders who were transferred to SAFPF after their administrative parole hearings. The low was 0 while the high was 9 MI offenders (see Figure 8).

Table 10 T-Test showed the N, Mean, Std. Deviation, and Std. Error Mean (see Table 10).

Table 11 showed Sig. (2-tailed) of 0.334, 0.347, 0.351, 391, 0.391, and 0.343 which were $>0.05$ or $>95 \%$ confidence interval of the differences; which showed a profound statistical significant differences in between and in within the data in this study. Pay attention to the lower and upper levels' significant differences (see Table 11). 
Table 8. Psychometric administrative hearings performances effects on SNOs in SNOP caseload.

\begin{tabular}{|c|c|c|c|c|c|c|c|}
\hline \multicolumn{8}{|c|}{ Psychometric Performances Effects } \\
\hline \multicolumn{8}{|c|}{ Administrative Hearings for SNOP in Region 3 in FY 2008 and FY 2009} \\
\hline & Not Revoked & Revoked & $\begin{array}{l}\text { Transfer to } \\
\text { ISF Facility }\end{array}$ & SAFPF & $\begin{array}{c}\text { Reopen Revocation } \\
\text { Hearing }\end{array}$ & $\begin{array}{c}\text { Go to Revocation } \\
\text { Hearing }\end{array}$ & $\begin{array}{c}\text { Total } \\
\text { Offenders }\end{array}$ \\
\hline Mentally Retarded & 21 & 5 & 26 & 0 & 0 & 3 & 55 \\
\hline Mentally Impaired & 699 & 269 & 641 & 9 & 6 & 99 & 1723 \\
\hline $\begin{array}{l}\text { Terminally } \\
\text { Ill/Physically } \\
\text { Handicapped }\end{array}$ & 41 & 11 & 17 & 0 & 0 & 4 & 73 \\
\hline $\begin{array}{c}\text { Mentally } \\
\text { Recommended } \\
\text { Intensive }\end{array}$ & 13 & 6 & 5 & 0 & 0 & 2 & 26 \\
\hline Total Offenders & 774 & 291 & 689 & 9 & 6 & 108 & 1877 \\
\hline
\end{tabular}

Table 9. Psychometric performances effects based on actual item response in SNOP caseload.

\begin{tabular}{|c|c|c|c|c|c|c|c|}
\hline \multicolumn{8}{|c|}{ Actual Item Response Effects } \\
\hline \multicolumn{8}{|c|}{ Percentages of Actual Item Responses within the SNOP Caseload } \\
\hline & $\begin{array}{c}\text { Not } \\
\text { Revoked }\end{array}$ & Revoked & $\begin{array}{l}\text { Transfer to } \\
\text { ISF Facility }\end{array}$ & SAFPF & $\begin{array}{c}\text { Reopen Revocation } \\
\text { Hearing }\end{array}$ & $\begin{array}{c}\text { Go to Revocation } \\
\text { Hearing }\end{array}$ & $\begin{array}{l}\text { Total } \\
\text { Offenders }\end{array}$ \\
\hline Mentally Retarded & 0.027 & 0.017 & 0.038 & 0.000 & 0.000 & 0.027 & 55 \\
\hline Mentally Impaired & 0.903 & 0.924 & 0.930 & 100.00 & $100.00 \%$ & 0.916 & 1723 \\
\hline $\begin{array}{l}\text { Terminally } \\
\text { Ill/Physically } \\
\text { Handicapped }\end{array}$ & 0.053 & 0.038 & 0.025 & 0.000 & 0.000 & 0.037 & 73 \\
\hline $\begin{array}{c}\text { Mentally } \\
\text { Recommended } \\
\text { Intensive }\end{array}$ & 0.017 & 0.021 & 0.007 & 0.000 & 0.000 & 0.019 & 26 \\
\hline Total \% & 100 & 100 & 100 & 100.00 & 100.00 & 100 & 1877 \\
\hline
\end{tabular}

Table 10. One-sample statistical T-Test for SNOs.

\begin{tabular}{ccccc}
\hline & & & \\
& One-Sample Statistics & Std. Error Mean \\
\hline Not Revoked & 4 & 193.50 & 337.21 & 168.60 \\
Revoked & 4 & 72.75 & 130.86 & 65.43 \\
Transfer to ISF Facility & 4 & 172.25 & 312.62 & 156.31 \\
SAFPF & 4 & 2.25 & 4.50 & 2.25 \\
Reopen Revocation Hearing & 4 & 1.50 & 3.00 & 1.50 \\
Go to Revocation Hearing & 4 & 27.0 & 48.01 & 24.01 \\
\hline
\end{tabular}

Table 11. One-sample test for SNOs.

\begin{tabular}{|c|c|c|c|c|c|c|}
\hline \multicolumn{7}{|c|}{ One-Sample test } \\
\hline & \multicolumn{6}{|c|}{ Test Value $=0$} \\
\hline & \multirow[t]{2}{*}{$\mathrm{t}$} & \multirow{2}{*}{ df } & \multirow{2}{*}{ Sig. (2-tailed) } & \multirow{2}{*}{ Mean Difference } & \multicolumn{2}{|c|}{$\begin{array}{l}\text { 95\% Confidence Interval of the } \\
\text { Difference }\end{array}$} \\
\hline & & & & & Lower & Upper \\
\hline Not Revoked & 1.148 & 3 & 0.334 & 193.5 & -343.07 & 730.07 \\
\hline Revoked & 1.112 & 3 & 0.347 & 72.8 & -135.5 & 281.00 \\
\hline Transfer to ISF Facility & 1.102 & 3 & 0.351 & 172.3 & -325.20 & 669.70 \\
\hline SAFPF & 1.000 & 3 & 0.391 & 2.25 & -4.91 & 9.41 \\
\hline Reopen Revocation Hearing & 1.000 & 3 & 0.391 & 1.50 & -3.274 & 6.274 \\
\hline Go to Revocation Hearing & 1.125 & 3 & 0.343 & 27.0 & -49.39 & 103.39 \\
\hline
\end{tabular}




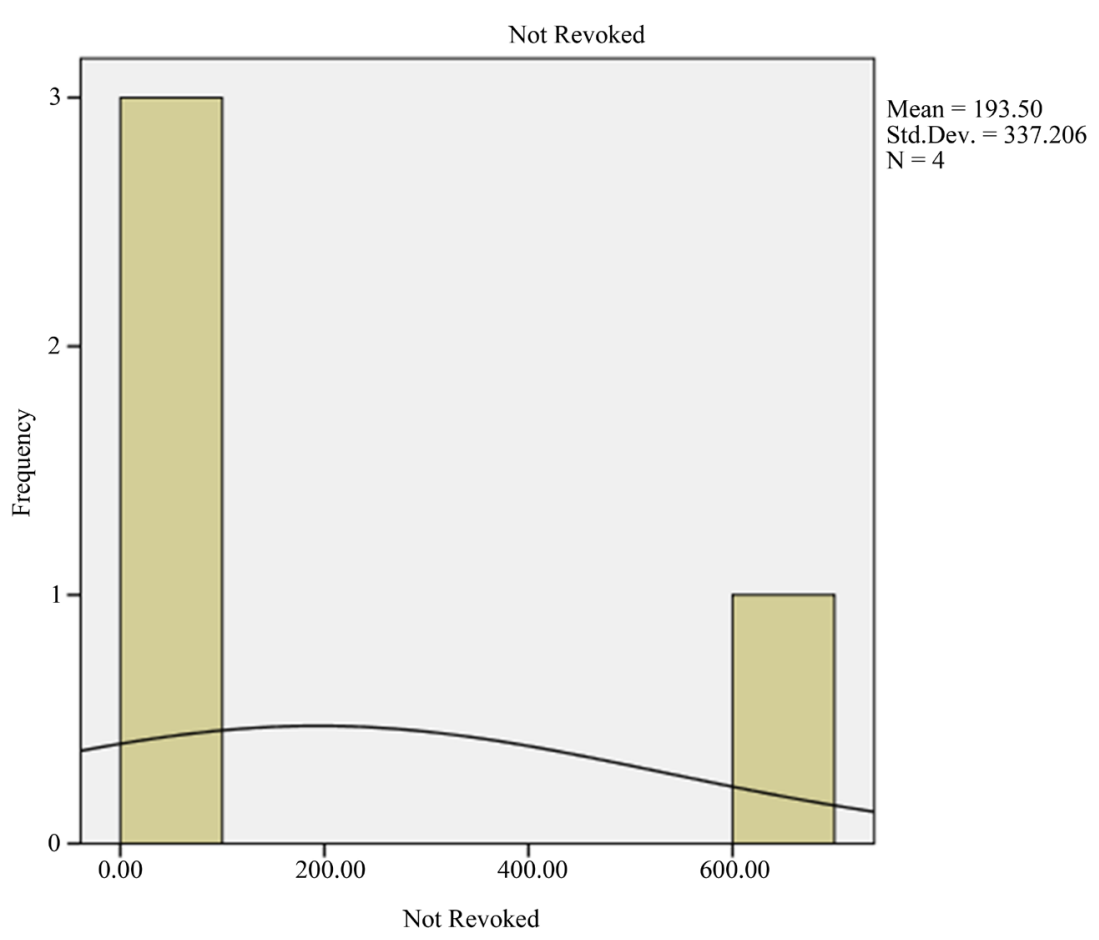

Figure 1. Not revoked SNOs.

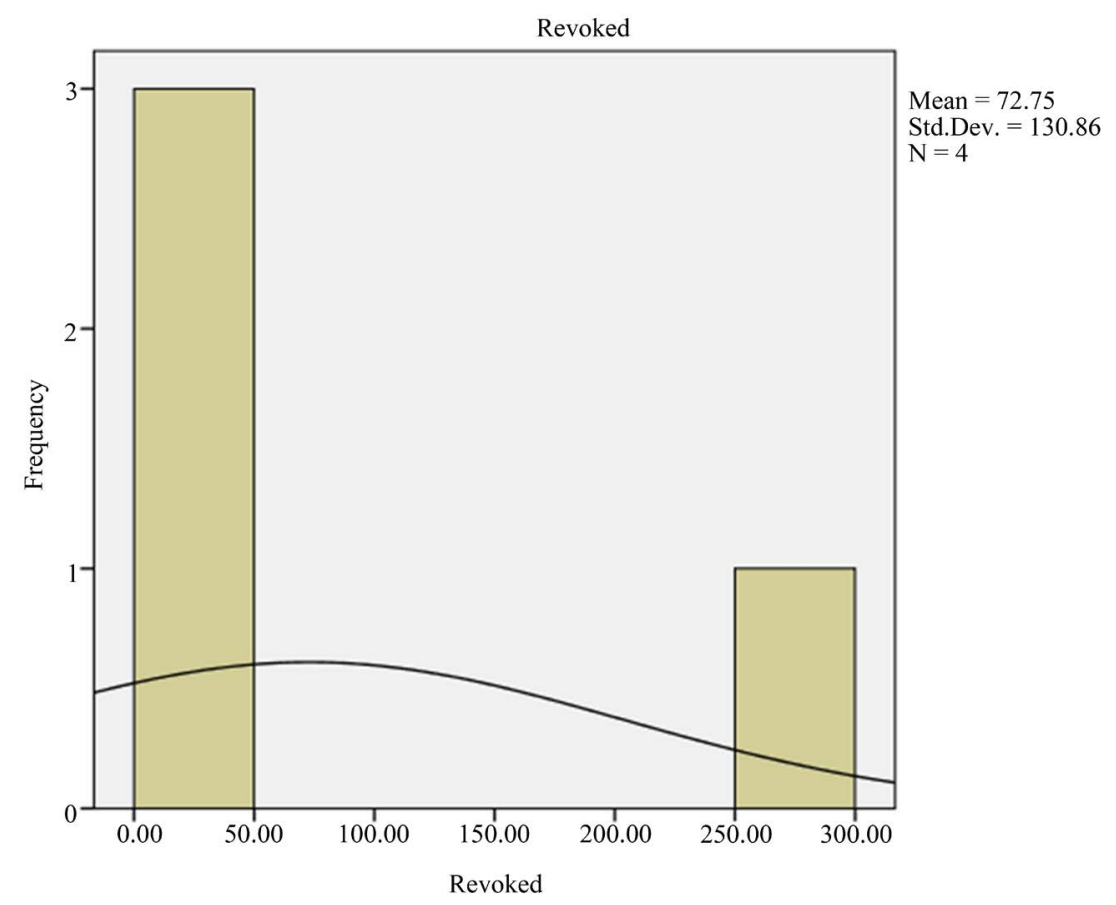

Figure 2. Revoked SNOs.

\section{Discussion of the Findings}

11. 1. Psychometric Performances' Effects Result on SNOs in SNOP Caseload

We found that in-between and in-within the SNOs caseload, when psychometric test scale was used to measure the collected data, even within the SNOs caseload, MI offenders overly performed to the measurement scale as 


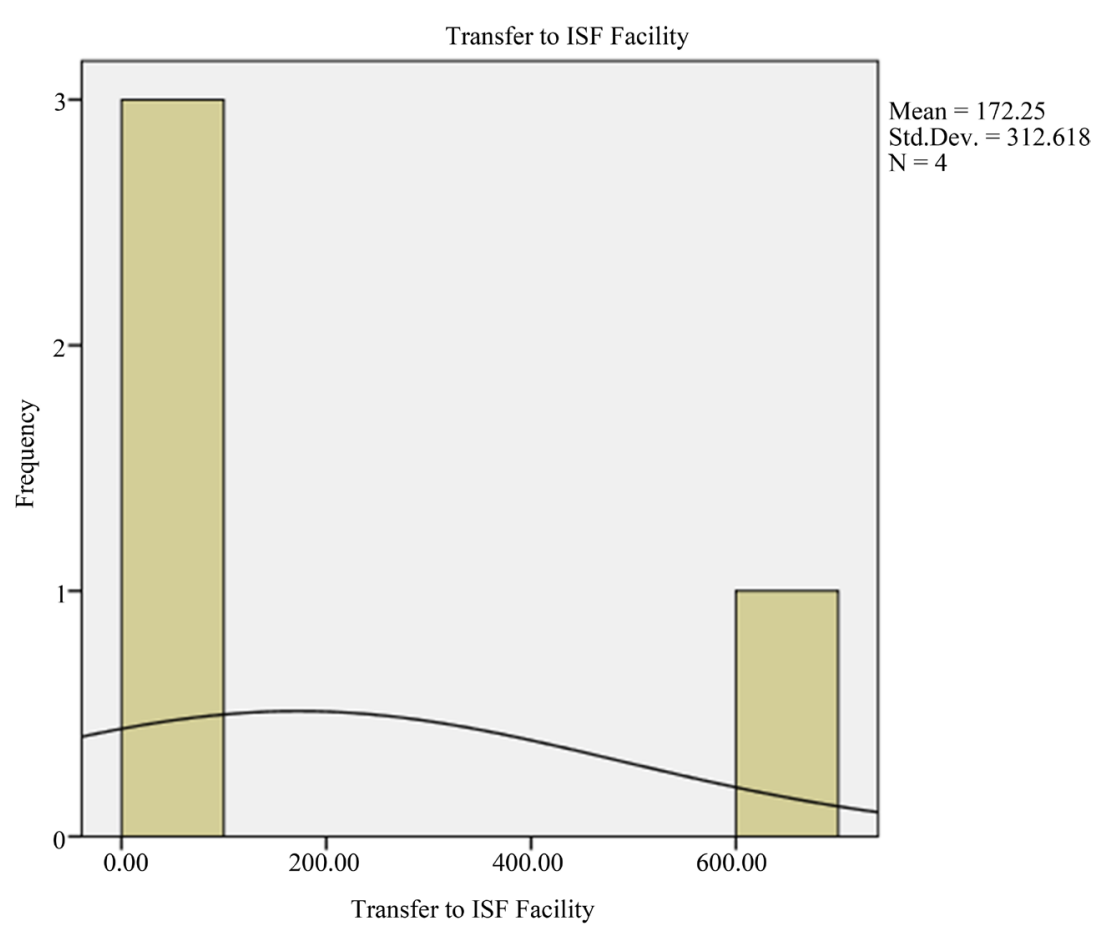

Figure 3. SNOs transferred to ISF facility.

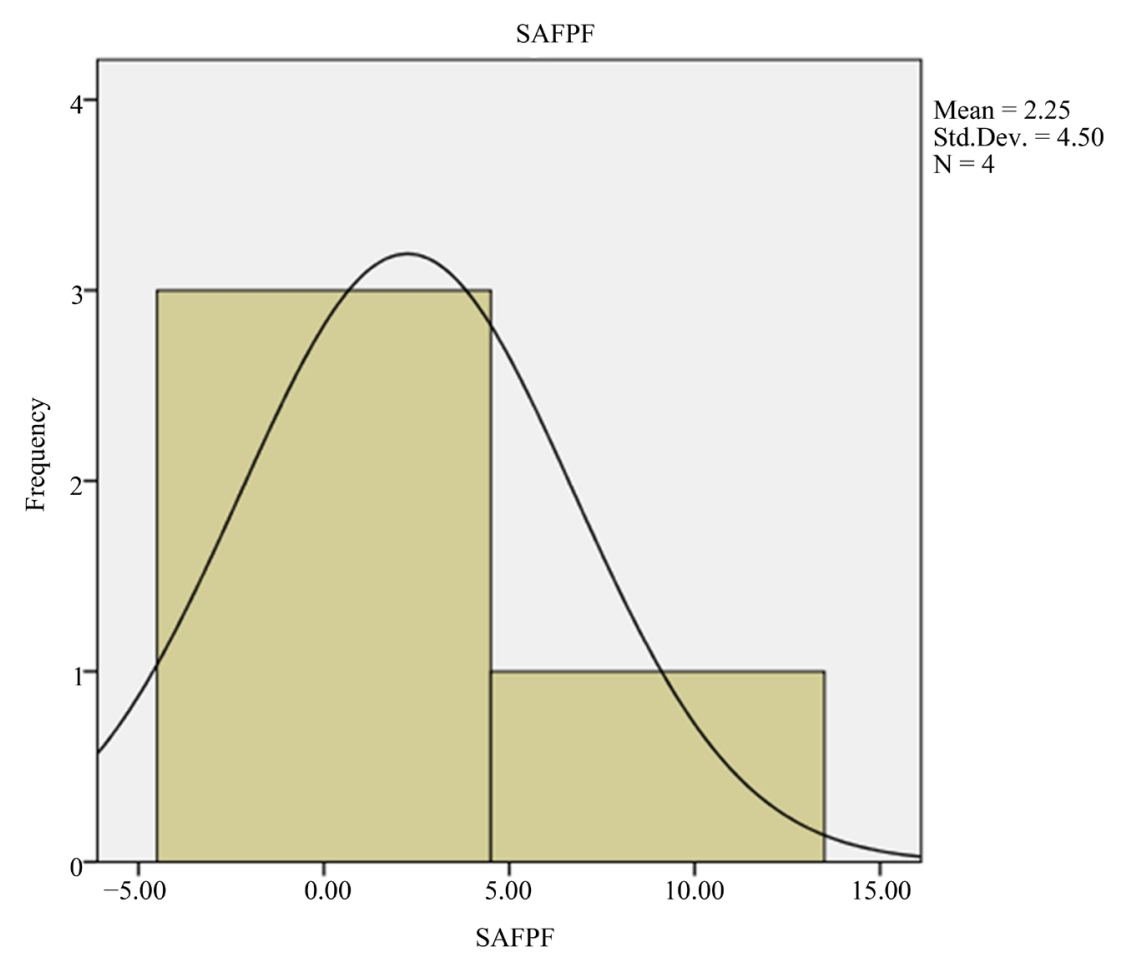

Figure 4. SNOs transferred to SAFPF.

compared to others SNOs in the SNOP caseload. This overreactions or over performances were so profound that it appeared that MI, MR, TI/PH, and MRIS should not be classified or grouped into one supervisory level or caseload know as SNOP. For example, we found that in all areas dealing with violations and hearings, MI responded excessively in between and in within $92 \%$ to $100 \%$ in all measurement categories. Additionally, we 


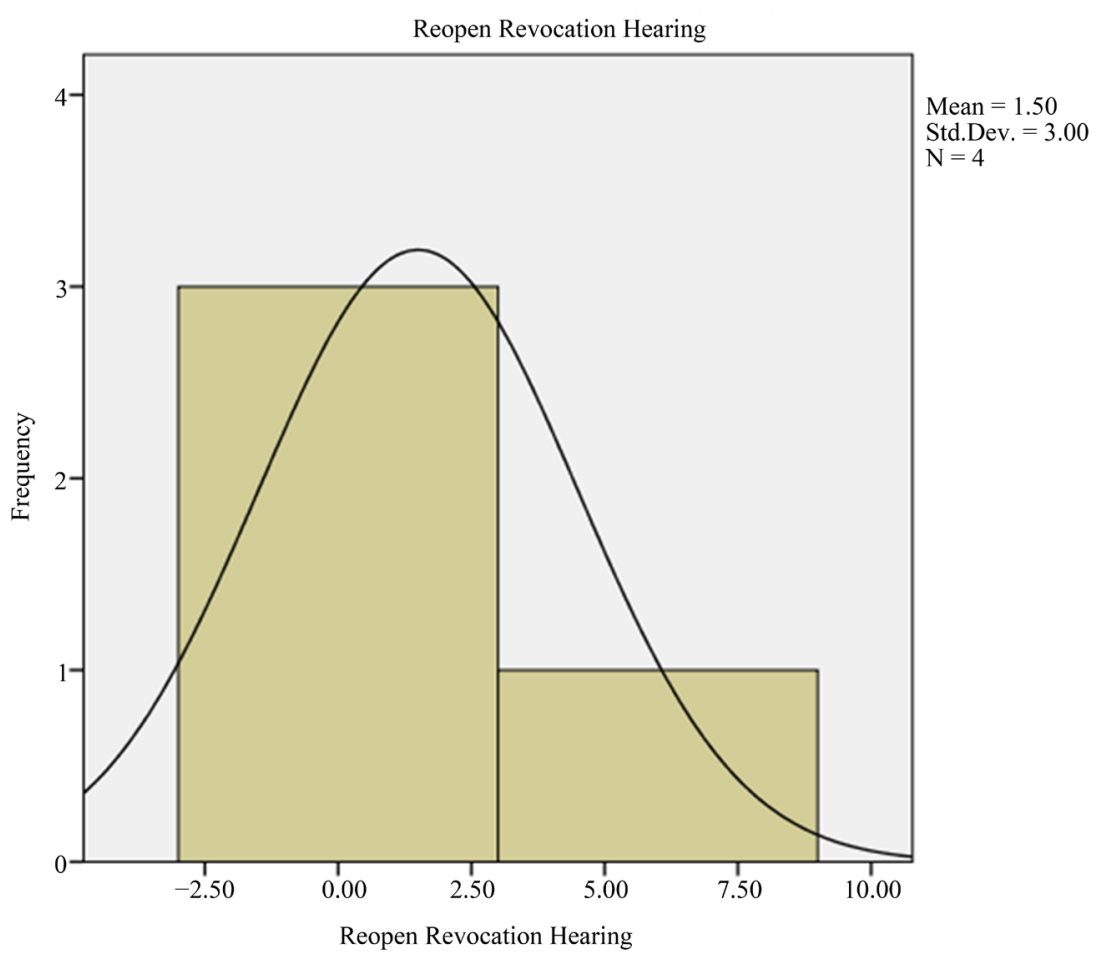

Figure 5. SNOs reopened revocation hearings.

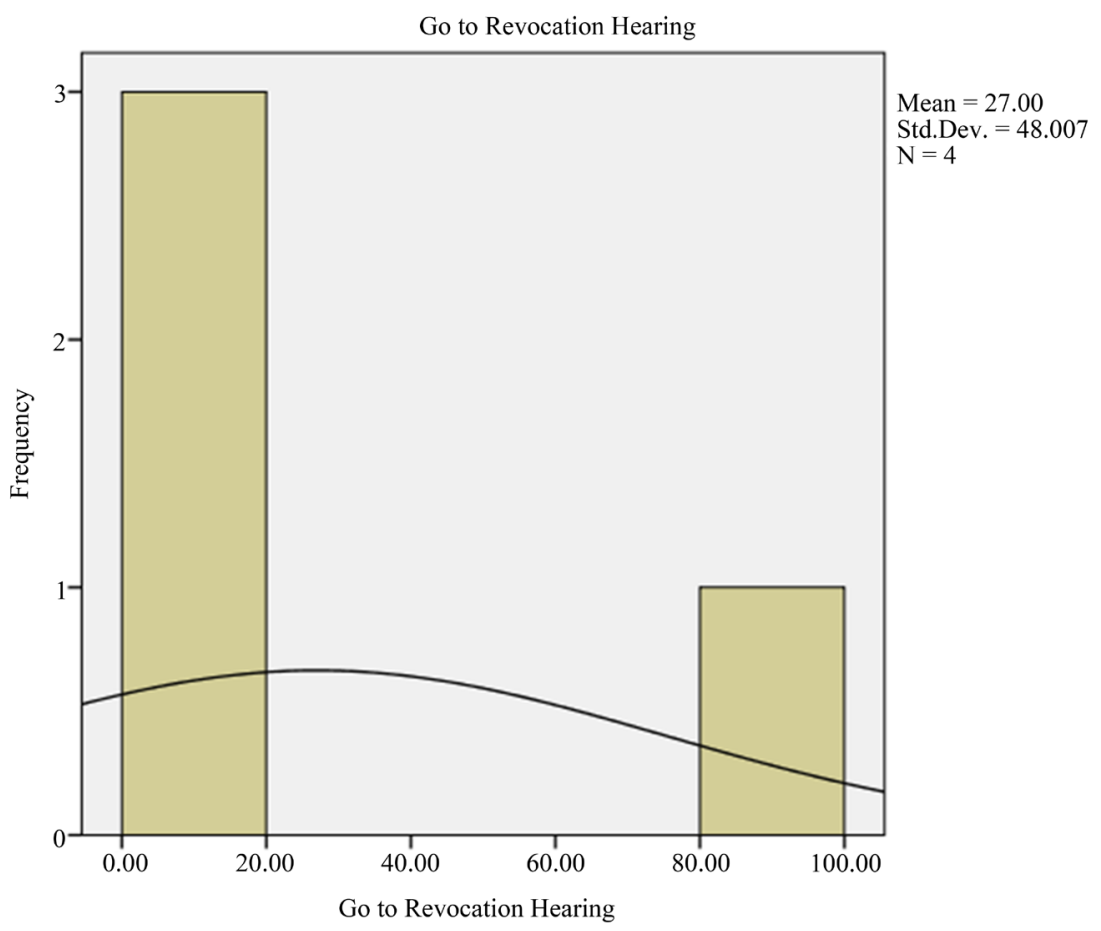

Figure 6. SNOs to go to revocation hearings.

found that of the 1877 SNOP hearings conducted in Region 3 between 2008 and 2009, MI accounted for $90 \%$ or 699 out of 774 of offenders not revoked. Within the same period, MI offenders accounted for approximately 93\% or 269 out of 291 of paroles that were revoked. Also, MI offenders accounted for $93 \%$ or 641 out of 689 transfers to ISF facilities, $100 \%$ transfer to SAFPF, and for a $100 \%$ of all reopened revocation hearings in Region 3. 


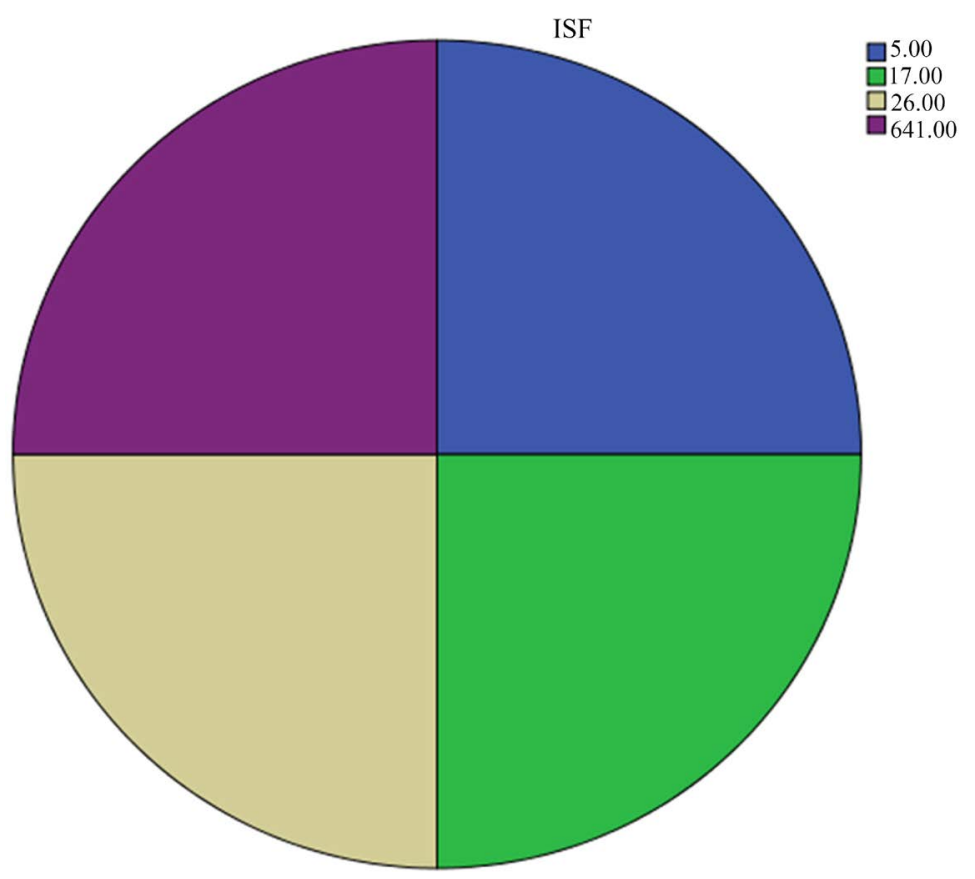

Figure 7. Pie chart representation of SNOs transferred to ISF.

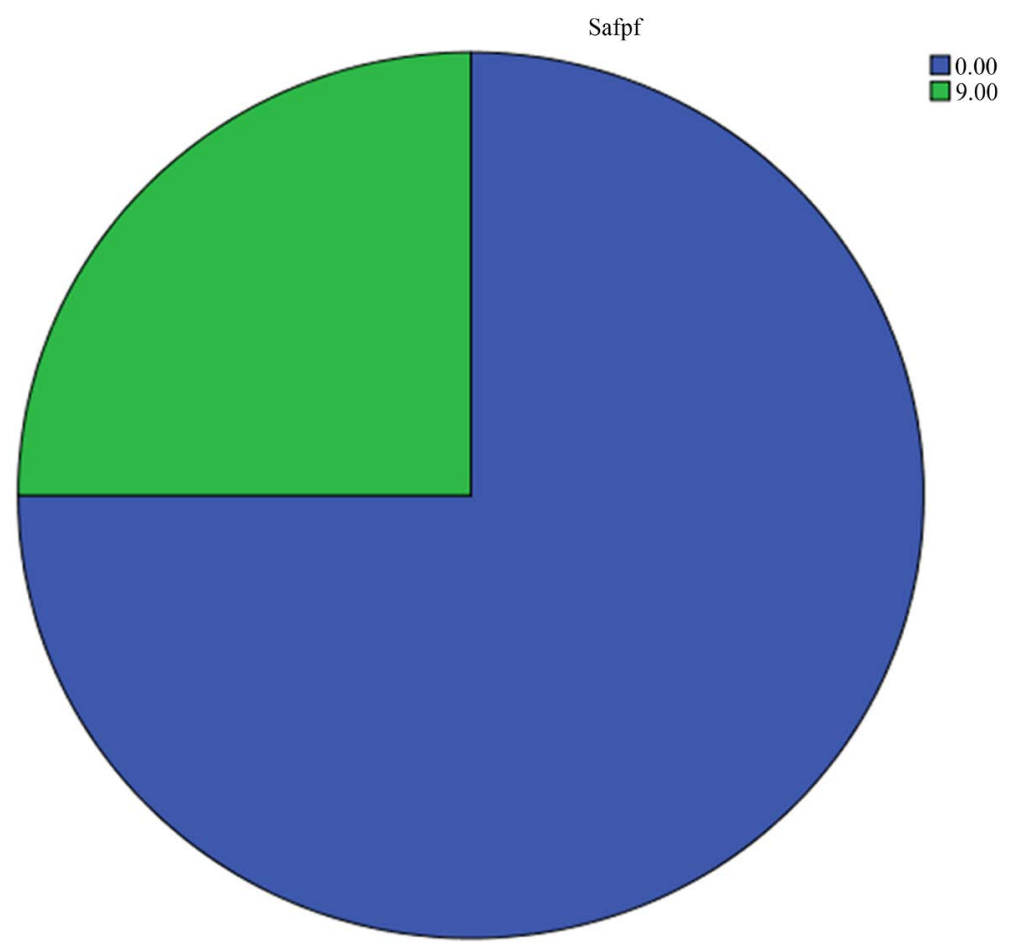

Figure 8. Pie chart representation of SNOs transferred to SAFPF.

The same years (2008 \& 2009), MI accounted for approximately 92\% or 99 out of 108 of all "Go to Revocation Hearing” Texas BPP recommendation in Region 3. Finally, MI offenders accounted for $92 \%$ or 1723 out of 1877 of all SNOP hearings conducted in Region 3 in 2008 and 2009.

As such, the roles MI offenders played in relationship to the psychometric test scale were something we did not anticipate and they were addressed in the recommendation section of this study. 
As for the central research question "What are the relationships between classification of SNOs and the implementation of SI-1 in the psychometric effects of offenders' performances?” We found that the ideologies behind the development and implementation of SI-1 supervision level imposed on the SNOs in supervised in the SNOP caseload in Austin, Colorado, and Fort Bend Counties, Texas created a higher recidivism rates for SNOs offenders; in particularly MI in-within and in-between the SNOP classified caseload. Theoretically and practically speaking, SNOP classification of SNOs with implementation of SI-1 supervision level fell into the premises of social construction or reconstruction of ideology of reality theory. Social construction and reconstruction of ideology of reality theory stipulated that ideology is initiated from possibly one individual gossip to a group gossips and to community; then to society, and sometimes used as a yardstick for public policy genesis, development, and implementation [16]-[19]. As such, we summed that the classification of SNOs and the implementation of SI-1 supervision level in SNOP caseload fell under the premises of social construction or reconstruction of ideology of reality theory.

Finally, We also found that MI offenders in between and in within the SNOP caseload were more than 92\% more likely to end up in Texas Parole Revocation Hearings as compared to less than 8\% likelihood for MR, TI/PH, and MRIS combined. This finding was statistically conclusive enough to sum that SI- 1 created social and supervisory implications of the MI offenders within the SNOP caseload as compared to other SNOP offenders as compared to MI, MR, TI/PH, and MRIS due their psychometric under performances and zero performances' effects in some cases. However, I could not itemize the specifics of such social or supervisory implications due to missing data which were not part of this study. In short, in relationship to the Risks/Needs/Responsivity (RNR see [9]-[16]) Theory's classification, which was designed to classify SNOs, based on their needs principles, risks principles, and responsivity principles this approach passed and failed in certain areas.

In terms of needs and risks principles the classification fell under efficacy supervision of SNOs in general. But, to answer research question 2: "What are the relationships between classification of SNOs and the implementation of SI-1 in the psychometric effects of offenders' performances collectively and individualized supervision?” Based on the psychometric performances' effects on the SNOs, in particularly the over psychometric performances associated with the MI and the under or in some cases zero (0) psychometric performances associated with MR, TI/PH, and MRIS, the study found that collectively and individually effective in the needs of the SNOs in SNOP caseload; but it was ineffective, inefficient, and in proficient the risks and responsivity principles of the RNR theory. As to respond to research question, the relationship between the classifications of SNOs under the supervision of SI-1 had positive psychometric performances' effects on MI and profoundly negative psychometric performances' effects on MR, TI/PH, and MRIS due to under or zero performances. In other words, the collective classification of MR, TI/PH, and MRIS with MI as SNOs under the supervision of SI-1 level in the SNOP caseload also fell under the Lurigio et al. [16] premises as an unreasonable accommodation for MR, TI/PH, and MRIS but not the MR. The positive intent for MR, TI/PH, and MRIS as SNOs supervised with SI-1, under the classification of the SNOP caseload was missing based on the overwhelming findings of this study.

\section{Statistical Analyses of the Study's Findings}

As previously stated, we hypothesized this study with two major hypotheses which were:

\section{1) Alternative Hypothesis H11:}

There was a direct relationship between classification of SNOs and the implementation of SI-1 in the psychometric effects of offenders' performances.

\section{2) Null Hypothesis H01:}

There was no relationship between classification of SNOs and the implementation of SI-1 in the psychometric effects of offenders' performances.

The study found that the analyses of the independent variables T-Test there was a profound statistical significant variances' differences in between and in within the participants of this study. For example, MI showed an overwhelming over psychometrical performance effects than MR, TI/PH, and MRIS combined in all measurements (see Table 1, Table 10, Table 11). Furthermore, in a One Way Sample test that was conducted, MI once again overwhelmingly over psychometrically out performed MR, TI/PH, and MRIS (see Tables 2-9, Table 11).

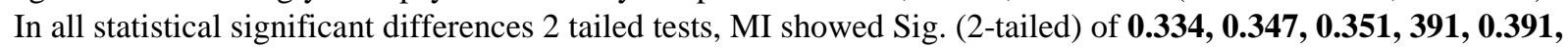
and $\mathbf{0 . 3 4 3}$ which were $>0.05$ which exceeded $95 \%$ Confidence Interval of the Difference. Based on these statistical 
findings we rejected the Null Hypothesis $\mathrm{HO} 1$ that "There was no relationship between classification of SNOs and the implementation of SI-1 in the psychometric effects of offenders' performances.” And, we accepted Alternative Hypothesis HI1, "There was a relationship between classification of SNOs and the implementation of SI-1 in the psychometric effects of offenders' performances."

\section{Confirmation of the Assumptions}

Finally, the study confirmed the three assumed assumptions 1, 2, and 3 prior to conducting this study that;

1) Assumption 1:

Classification of SNOs and the implementation of SI-1 lead to psychometric effects of offenders' groups' overly performances.

\section{2) Assumption 2:}

Classification of SNOs and the implementation of SI-1 lead to psychometric effects of offenders' group under performances.

\section{3) Assumption 3:}

There is no doubt that the classification of SNOs and the implementation of SI-1 led to psychometric effects of offenders' group as over, under, no, or zero performances. In every tests conducted in this study, the statistical findings indicated that assumptions 1, 2, and 3 stood as assumed (see Tables 1-11 \& Figures 1-8).

\section{Limitation of the Study}

This study showed three major limitations which are enlisted below;

1) This is a "Multiple Case Study" that dealt only with data collected from TDCJ-PD Region 3 area Administrative Parole Hearings which may not be holistically generalized in all areas in the state of Texas and possibly beyond.

2) The requested, released, and reviewed data did not contain whether these violations were Technical Violations rules; which are related to parole officers' instructions and imposed special conditions or if they were New Law Violations which are related to new law criminal activities.

3) Finally, the data requested, released, and reviewed did not indicate the total population of MI, MR, TI/PH, and MRIS which could have shed some additional statistical lights on the reasons for the overly skewed psychometric performances effects of this study's findings.

\section{Implication of the Study}

This study shed three major implications on SNOs classification to be collectively supervised with SI-1 in SNOP caseload. First, the study found that while classification of SNOs under the supervision of SI-1 in SNOP caseload was effective, efficient, and proficient when dealing with groupings and not when it comes to supervision efficacies. This is the case because MI outperformed MR, TI/PH, and MRIS in all dimensions associated with the psychometric performances' effects tests (see Tables 1-11 \& Figures 1-8). The cumulative frequencies as show in Tables 2-7 are overwhelming in all areas of measurements. Secondly, in some cases, MI showed over performances that ranged from $90 \%$ plus to $100 \%$ collectively; while MR, TI/PH, and MRIS showed under or no performances that ranged from $0 \%$ to $9 \%$ collectively across the board. This showed that classification of SNOs under the supervision of SI-1 in SNOP caseload was ineffective, inefficient, and in proficient to these three groups (sees [16]-[19]). It further showed that MR, TI/PH, and MRIS were given unreasonable accommodation as argued by ([16]). Finally, the study showed that when dealing with RNR, MI was under dosed and MR, $\mathrm{TI} / \mathrm{PH}$, MRIS were overdosed due to their responsivity principles. The needs principles and the risk principles were met; but, the responsivity principles were obvious. The performances of MR, TI/PH, and MRIS fell under the social construction and reconstruction of ideology of reality theory.

\section{Discussion and Conclusion}

In summation, the primary purpose of the classification of SNOs under the supervision of SI-1 level in SNOP caseload since 1995 was to enhance the marginal propensity that SNOs successfully complete parole supervision under the supervision of a specialized parole SNOP officer who is assigned to the caseload. However, the study found that while the classification of SNOs to be supervised with SI-1 in SNOP caseload was effective in needs 
principles and risks principles grounds, it was ineffective, inefficient, and in proficient because classification played a significant psychometric performances' effects on the MR, TI/PH, and MRIS as compared to the MI. While it may be arguable that MI simply overly performed due to their larger population size in the SNOP caseload as compared to others; but, this was not the case because their total psychometric performances effects exceeded the actual statistical population size in all areas. The study further found that the classification of SNOs showed that MR, TI/PH, and MRIS were practically overdosed while MI was under dosed based on RNR theory that addressed the functionalities of their responsivity. In fact, it appeared that the classification of SNOs under the supervision of SI-1 in the SNOP caseload operated under long-term operational default since 1995 due to MI psychometric performances outcomes. As such, the study concluded that MI indeed was an overly active functionality factor in the SNOP caseload due to its unequivocal psychometric performances' effects.

Finally, the study found that the classification of SNOs to be supervised with SI-1 level in SNOP caseload was under the stigmatization, assumptions, and presumptions of unreasonable accommodation and expectation ([8]) for MR, TI/PH, and MRIS which indeed also fell under social construction or reconstruction of ideology of reality theory ([16]-[19]) which stressed that skewed policies' ideologies, initiation, development, and implementation. These findings shed some valuable lessons learned and insights gained to all classification modalities. In other words, that was the outcomes of the SNOs supervised with the SI-1 in the SNOP caseload in the state of Texas. Essentially, from a criminal justice, public health, public policy, and possibly for profit organization policy standpoints, the findings of this study need to be holistically revisited symmetrically and systematically as to possibly bring some positive social changes to SNOs in the state of Texas and possibly beyond.

\section{Recommendations}

The recommendations of the study are as followed;

\subsection{TDCJ-PD}

1) TDCJ-PD should rethink and revisit SNOs classification under the supervision of SNOP caseload with SI-1 as to reassess and reevaluate its efficacy on the compliances and non compliances of these offenders.

2) TDCJ-PD should rethink and revisit SNOs classification under the supervision of SNOP caseload with SI-1 as to reassess and reevaluate its responsivity effects on MR, TI/PH, and MRIS in this caseload.

3) Finally, TDCJ-PD should revisit and reevaluate the efficiency, effectiveness, and proficiency of SNOs in SNOP caseload as to review their psychometric performances effects as to possibly redesign the SNOP caseload.

4) TDCJ-PD should rethink and revisit SNOs classification under the supervision of SNOP caseload with SI-1 supervision level and administratively systematically twig their supervision levels which could bring some social supervision efficacies and possibly bring some positive social changes to the SNOs in SNOP caseload.

\subsection{BPP}

1) BPP should rethink and revisit the SNOP caseload during Texas parole administrative hearings by identifying the violations of the SNOs in the SNOP caseloads.

2) BPP should revisit and revisit the SNOP caseload during Texas parole administrative hearings by individual counting MI, MR, TI/PH, and MRIS population in the annually hearing process.

3) Finally, BPP should rethink and revisit the general psychometric performances effects on the SNOs in the SNOP caseload during the annually hearing process.

\subsection{For Profit Organizations}

1) Profit organizations should know that the classification of over performances with under or no performances employees leads to overall mixed or positive psychometric performances effects which increases profit.

2) Secondly, the classification of underperformances or nonperformance with overly performances employees' leads to mixed or negative psychometric performances effects marginalizes profit.

3) Thirdly, the classification of underperformance with nonperformance employees singularly, leads to negative psychometric performances effects which decrease profit.

4) Finally based on the findings of this study, for profit organizations should understand that whenever overly 
psychometrically performed employees are intentionally, systematically, symmetrically, or accidentally classified into one group, the group's earnings will go up simultaneously; and, if revise is the case, the earnings will drop significantly immediately.

\section{Acknowledgements}

The researchers thank University of Phoenix, Prairie View A\&M University, and the BPP Administrator

Tim McDonnell for assisting us with the data of this study. This is a researchers' self funded study.

\section{Conflict of Interests}

We shared no conflict of interests in this study.

\section{References}

[1] Texas Department of Criminal Justice-Parole Division (TDCJ-PD) (2011) Parole-Directives. Austin, Texas. http://www.tdcj.state.tx.us/

[2] TDCJ-Parole Division (2007) PD/POP 3.6.2 Sex Offenders Program Supervision Guidelines. http://www.tdcj.state.tx.us/documents/parole/03.06.02_parole_policy.pdf

[3] TDCJ-Parole Division (2011) PD/POP-3.5.1 Electronic Monitoring Program. http://www.tdcj.state.tx.us/documents/parole/03.05.01_parole_policy.pdf

[4] Bernstein, M.S. (2008) A Comparison of Mentally Ill Detainees Who Opt-in or Opt-out of Mental Health Court. Doctoral Dissertation, Nova Southeastern University, Davie. http://gradworks.umi.com/33/49/3349292.html

[5] Buchanan, R. (2008) An Investigation of Predictors of Educational Engagement for Severely Antisocial. Doctoral Dissertation, Girls University of Oregon, 1-104. http://gradworks.umi.com/33/25/3325647.html

[6] Dickins, J.E. (2007) Evaluating the Effectiveness of a Manualized Treatment for Inmates with Dual Diagnoses. University of Nevada, Las Vegas, 1-157. (Published dissertation, Available at (Walden Library) doi: \# AAT 3282002)

[7] Hutchins, A.M. (2008) An Assessment of School Enrollment Status among a Sample of African-American Male Juvenile Ex-Offenders At-Risk for Violent Behaviors. Morgan State University, Baltimore, 1-92. http://gradworks.umi.com/33/36/3336913.html

[8] Lurigio, A.J., Gudenberg, K.A. and Spica, A.F. (1988) Working Effectively with AIDS (Acquired Immune Deficiency Syndrome) Cases on Probation. Perspectives, 12, 10-15.

[9] Andrews, D.A., Bonta, J. and Wormith, J.S. (2006) The Recent Past and Near Future of Risk and/or Need Assessment. Crime \& Delinquency, 52, 7-27. http://dx.doi.org/10.1177/0011128705281756

[10] Andrews, D.A. and Bonta, J. (2006) The Psychology of Criminal Conduct. 4th Edition, LexisNexis, Newark, NJ.

[11] Arnold, T. (2007) Dynamic Changes in the Level of Service Inventory-Revised (LSI-R) and the Effects on Prediction Accuracy. Unpublished Master's Dissertation, St. Cloud University, St. Cloud, Minnesota.

[12] Ward, T., Mesler, J. and Yates, P. (2007) Reconstructing the Risk-Need-Responsivity Model: A Theoretical Elaboration and Evaluation. Aggression and Violent Behavior, 12, 208-228. http://dx.doi.org/10.1016/j.avb.2006.07.001

[13] Bourgon, G., Bonta, J., Rugge, T., Scott, T.L. and Yessine, A.K. (2009) Translating "What Works" into Sustainable Everyday Practice: Program Design, Implementation and Evaluation. Public Safety Canada, 1-23.

[14] Raynor, P. (2004) The Probation Service "Pathfinders": Finding the Path and Losing the Way? Criminal Justice, 4, 309-325. http://dx.doi.org/10.1177/1466802504048468

[15] Raynor, P. (2008) Community Penalties and Home Office Research: On the Way Back to "Nothing Works"? Criminology \& Criminal Justice, 8, 73-87. http://dx.doi.org/10.1177/1748895807085870

[16] Trotter, C. (1996) The Impact of Different Supervision Practices in Community Corrections: Cause for Optimism. Australian and New Zealand Journal of Criminology, 29, 1-18. http://dx.doi.org/10.1177/000486589602900103

[17] Andrews, D.A. and Bonta, J. (2003) The Psychology of Criminal Conduct. 3rd Edition. Anderson, Cincinnati, OH.

[18] Berger, P.L. and Luckmann, T. (1966) The Social Construction of Reality: A Treatise in the Sociology of Knowledge. Doubleday \& Company, New York.

[19] Wilden, A. (1987) The Rules Are No Game, the Strategy of Communication. Routledge \& Kegan Paul, Londres et. New York, New York, 432 p.

[20] Creswell, J.W. (2009) Research Design: Qualitative, Quantitative, and Mixed Methods Approach. 3rd Edition, Sage Publications, Inc., Thousand Oaks, CA. 
[21] Miller, R.G. (1981) Simultaneous Statistical Inference. 2nd Edition, Springer-Verlag, New York. http://dx.doi.org/10.1007/978-1-4613-8122-8

[22] Morrow, J. (2011) Laureate Education, Inc. (2011 Executive Producer), (Walden, [DVD]). The t-Tests for Independent Variables/Introduction to Hypothesis. Laureate Education, Inc., Baltimore. (Available at: Walden Study Resources, week 7, RCSH-8200P-2)

[23] Frankfort-Nachmias, C. and Nachmias, D. (2000) Research Methods in the Social Sciences. 6th Edition, Wadsworth, New York.

[24] Frankfort-Nachmias, C. and Nachmias, D. (2008) Research Methods in the Social Sciences. 7th Edition, Worth, New York.

[25] Smilde, A.K., Jansen, J.J., Hoefsloot, H.C.J., Lamers, R.-J.A.N., van der Greef, J. and Timmerman, M.E. (2005) ANOVASimultaneous Component Analysis (ASCA): A New Tool for Analyzing Designed Metabolomics Data. Bioinformatics, 21, 3043-3048. http://dx.doi.org/10.1093/bioinformatics/bti476

[26] Jansen, J.J., Hoefsloot, H.C.J., van der Greef, J., Timmerman, M.E., Westerhuis, J.A. and Smilde, A.K. (2005) ASCA: Analysis of Multivariate Data Obtained from an Experimental Design. Journal of Chemometrics, 19, 469-481. http://dx.doi.org/10.1002/cem.952

[27] Vis, D.J., Westerhuis, J.A., Smilde, A.K. and van der Greef, J. (2007) Statistical Validation of Megavariate Effects in ASCA. BMC Bioinformatics, 8, 322. http://dx.doi.org/10.1186/1471-2105-8-322

[28] Smilde, A.K., Hoefsloot, H.C. and Westerhuis, J.A. (2008) The Geometry of ASCA. Journal of Chemometrics, 22, 464-471. http://dx.doi.org/10.1002/cem.1175

[29] Texas Board of Pardon and Parole (BPP) (2009) Annual Report Fiscal Year (FY) 2009. http://www.tdcj.state.tx.us/bpp/publications/AR\%20FY\%202009.pdf

[30] Texas Board of Pardon and Parole (BPP) (2010) Annual Report Fiscal Year (FY) 2010. http://www.tdcj.state.tx.us/bpp/publications/AR\%20FY\%202010.pdf

[31] Texas Board of Pardon and Parole (BPP) (2011) Annual Statistical Report Fiscal Year (FY) 2011. http://www.tdcj.state.tx.us/bpp/publications/BPP\%20StatisticalReport_08-08-2012.pdf 